\title{
Mathematical model for calculating the parameters of machines for processing near- trunk strips in a terrace
}

\author{
Aslan Apazhev, Artur Egozhev*, Magomed Misirov, Evgeny Polishchuk, and Asker \\ Egozhev
}

Kabardino-Balkarian State Agricultural University named after V.M.Kokov, Lenin Avenue, 1V, 360030 Nalchik, Russia

\begin{abstract}
Horticulture is one of the most dynamically developing branches of agricultural production. In recent years, in the Russian Federation, there has been an annual increase in the area for gardens, including on sloping lands, gross harvest and good yield. In the conditions of the foothill zone of the North Caucasus, the most promising direction is the development of slope lands, with favorable soil and climatic conditions for the cultivation of fruit crops. The design features of the terraces impose restrictions on the operating conditions of agricultural units, among the many it is necessary to emphasize the possibility of approaching the row line for processing the near-trunk circle from only one side. Most of the horticultural businesses have mainly equipment designed for work in flat gardening conditions, which for complete processing requires the passage of the unit along each side of the row line that cannot be provided in terraces. A design technology scheme of the machine working tool is proposed, the technical result of which lies in the performance of a highquality processing in the zone of the near-trunk circle by ensuring the bypass of rotors with cutting segments around the tree trunk, without its damaging, in one passage of the unit along the row line.
\end{abstract}

\section{Introduction}

Terracing in the conditions of limited areas for land use makes it possible to develop the slopes of the North Caucasus for gardens $[1,2]$. The air temperature is on average $0.5-0.6^{\circ} \mathrm{C}$ higher on terraces than on ordinary slopes, and the thermal regime is also significantly improved [2 4].

Among the variety of different methods of soil maintenance in gardens, in conditions of slope gardening, in order to minimize soil erosion processes, as well as provide plants with moisture and the required nutrients, a sod humus system is used, which provides for periodic mowing of vegetation growing in the spacing and near-trunk strip for mulch $[5,6]$.

Modern industrial horticulture at this stage is a capital-intensive branch of agriculture, the effectiveness of which is achieved through the use of new production means and

* Corresponding author: artyr-egozhev@yandex.ru 
technologies. The main problem that producers face is the lack of modern technology for the care of the spacing and near-trunk strips of intensive fruit plantations.

The design features of the terraces impose restrictions on the operating conditions of agricultural units, among the many it is necessary to emphasize the possibility of approaching the row line for processing the near-trunk circle from only one side. Most of the horticultural businesses have mainly equipment designed for work in flat gardening conditions, which for complete processing requires the passage of the unit along each side of the row line that cannot be provided in terraces [7,8].

Based on the above mentioned, it can be concluded that the introduction of new machines and units for processing the near-trunk circle (mowing and milling) in one passage of the unit, ensuring an increase in soil fertility on sloping lands, is relevant.

\section{Materials and methods}

A mathematical model is proposed for determining the basic kinematic and dynamic parameters of the machine working tool for processing the zone of the near-trunk circle of fruit trees of an intensive garden in one passage of the unit [8-12].

Let's consider the operation of the working tool during the technological process in the zone of the near-trunk circle. A conventionally fixed coordinate system centered at a fixed point is $O$ denoted by $O x_{1} y_{1}$. A movable coordinate system is also centered at a point $O_{1}$, the axis $O_{1} y$ is directed along the line connecting the centers $O$ and $O_{1}$, the axis $O_{1} x$ is directed perpendicular to the axis $O_{1} y$. The coordinate system $O_{1} x y$ is rigidly connected to the disk and, therefore, moves with it along the guide circle of the radius $r_{2}$ at a constant angular velocity $\omega_{1}$. The movement of all points of the working tool in this case will be complex, and consists of a translational rotation around the axis with an $O_{1}$ angular velocity and $\omega$ relative movement around the $O$ axis with an angular velocity $\omega_{1}$.

We will preliminarily accept the condition that since the rotor speed to ensure the working process is much higher than the rotational speed of the rotary section around the tree trunk, we assume that the length of the arc is a circle $L=O_{1} O_{1}^{\prime}$. In this case, the calculation of the areas run through by the mower knife or the working part of the cutter can be carried out as for a circle. Then, in accordance with these assumptions, the working body will $a b$ process the area $S_{1}$, the next segment will $c d$ process the area $S_{2}$. The crosshatched area, bounded by the circumferential lines of both segments $S_{x}$, defines the idle area of the second segment, since this part is processed by the segment $a b$.

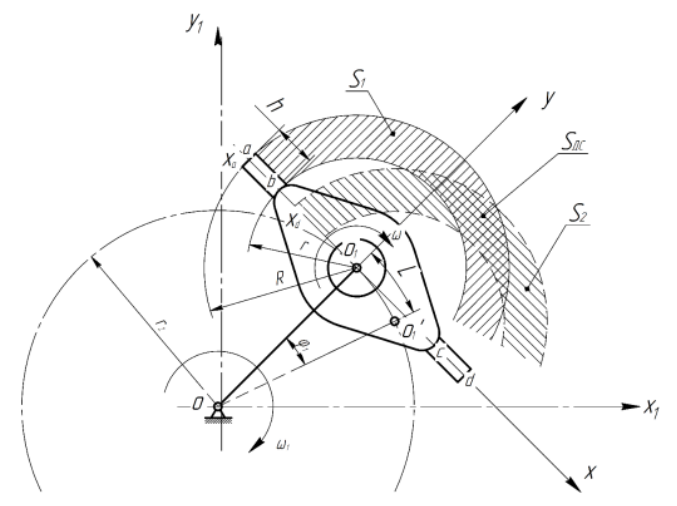

Fig. 1. Scheme for investigation of the working tool operation. 
Let the $t$ center of the disk $O_{1}$ move to the point $O_{1}^{\prime}$ at a moment of time, which will turn to the corner when the $O O_{1}$ crank turns $\varphi_{1}=\omega_{1} t$. At the same time, the center of the disk with working segments will turn to the corner $\varphi=\omega t$.

There will be no untreated site if

$$
x_{d}-x_{a}=h
$$

where $h$ - the length of the cutting segment, $\mathrm{m}$.

\section{Results and discussion}

In order to perform the process of mowing vegetation or milling around the tree trunk with proper quality (no knives or cutters) the following condition shall be complied:

$$
L=h
$$

where $L$ is the size of the path of the rotor center passing with cutting segments along the arc of the guide circle when it turns to the corner $\varphi, \mathrm{m}$.

The working part will $c d$ pass through the axis $x$ at the angle of the turn:

$$
\varphi=\omega t_{p}=\pi
$$

where $t_{p}$ there is a time that determines the rotation of the rotor with cutting segments at the desired angle, s.

The time of turning the disk to an $\varphi$ angle (when installed on the rotor of two cutting segments) shall be:

$$
t_{p}=\pi / \omega
$$

where there is an $\omega$ angular rotation velocity of the rotor with cutting segments, at $\mathrm{c}^{-1}$.

The value of the path passed by the center of the rotor when turning relative to the tree trunk:

$$
L=\pi r_{2} \varphi_{1} / 180=\pi r_{2} \omega_{1} t_{c} / 180
$$

where $\varphi_{1}$ is the value of the rotation angle of the rotary section around the tree trunk, degrees; $\omega_{1}$ is the angular velocity of rotation of the rotary section around the tree trunk, at ${ }^{-1} ; t_{c}$; is the time of rotation of the rotor with cutting segments at an angle $\varphi_{1}$, s.

The time in which the point $O_{1}$ will move into the position $O_{1}^{\prime}$ :

$$
t_{c}=180 L /\left(\pi r_{1} \omega_{1}\right)
$$

The condition of the quality functioning of the working tool will be in compliance with the requirement:

$$
t_{p} \leq t_{c}
$$

Substituting values (4) and (6) to the expression (7), taking into account (2), we shall obtain: 


$$
\pi / \omega \leq 180 h /\left(\pi r_{2} \omega_{1}\right)
$$

The expression (8) links the mode $\left(\omega, \omega_{1}\right)$ and the design parameters $(h)$ of the unit.

Let's determine the angular velocity of $\omega_{1}$ rotation by expressing it through the speed and movement of the energy vehicle. During the technical process, in general, the working body can be presented as a crank-slid mechanism with a guide axis that does not pass through the axis of the curve and the separated from it $d=$ const (Figure 2), and a takeaway rotary section with contacting, all over the technical process with the tree trunk jack wheels 1 and 2, in particular, as an epicyclical mechanism, in which moving wheels 1 and 2 (jack wheels) rolled over the stationary wheel 3 (tree trunk).

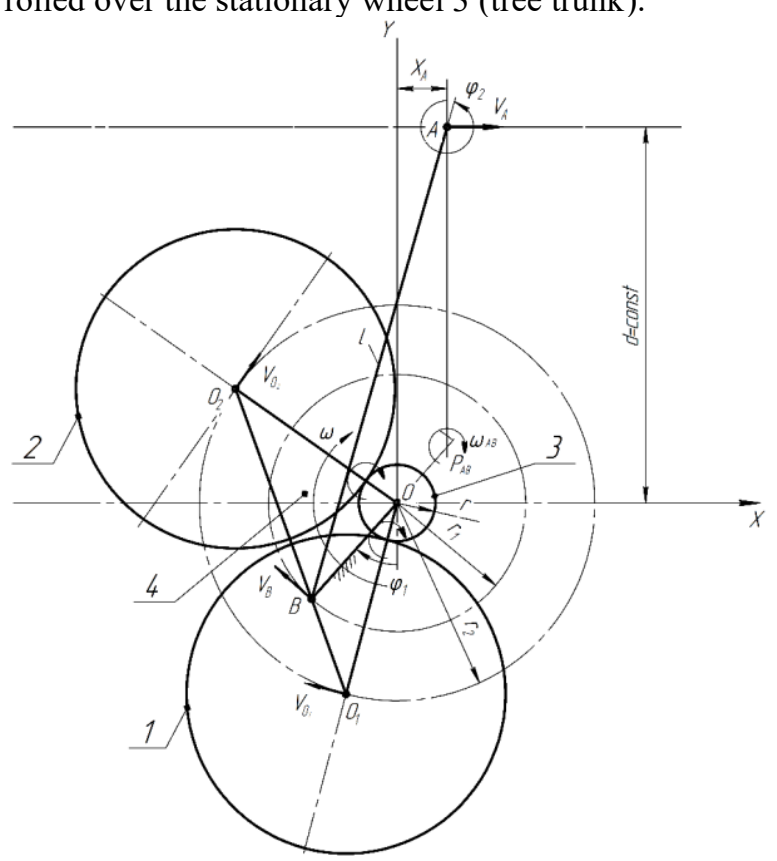

Fig. 2. Scheme to determine the main kinematic parameters of the takeaway rotary section.

The guide link in this mechanism is the $A$ slider (energy vehicle), the driven link is the link 4 rigidly connected with the crank of the $O V$. The translational movement of the slider $A$ at a constant speed $V_{A}$ in the direction of the $x$ axis causes the rotation of the $O V$ crank, as well as the link 4 rigidly connected to it, at a constant angular velocity $\omega_{1}$, forcing at the same time two wheels 1 and 2 to roll, without slipping, along a stationary wheel 3 . The elastic elements included in the design provide continuous contact of jack wheels with a tree trunk, so that the rotor centers with cutting segments move around the tree trunk with constant angular velocity $\omega_{1}$ along the guide circle.

The velocity of the point $V$, which belongs to the $O V$ crank, which rotates around the point $O$ in conjunction with the link 4, will be defined as:

$$
V_{B}=r_{1} \omega_{1}
$$

where $r_{1}=O B$ - the radius of the circle on which the point $V, \mathrm{~m} ; \omega_{1}$ moves; - the angular velocity of rotation of the crank of the $O V$, $\mathrm{rad} / \mathrm{s}$.

Point $V$ also belongs to the link $A V$, which makes a plane motion. 
The immediate velocity center of the $A V$ crank rod is located at the intersection of perpendiculars restored at points $A$ and $V$ to their velocity directions.

At the same time, the velocity of point $V$ is determined by the expression:

$$
V_{B}=V_{A} \cdot A P_{A B} / B P_{A B},
$$

where $A P_{A B}$ and $B P_{A B}$ - distances from points $A$ and $V$ to the instant center of velocities, correspondingly.

Taking into account the expression (10) the angular velocity of the $O V$ crank:

$$
\omega_{1}=V_{B} / r_{1}=V_{A} / r_{1} \cdot A P_{A B} / B P_{A B} .
$$

Distances $B P_{A B}$ and $A P_{A B}$ depending on movement $x_{A}$ can be defined as:

$$
A P_{A B}=d-x_{A} / \tan \varphi_{1} ; B P_{A B}=r_{1}-x_{A} / \sin \varphi_{1},
$$

where $\varphi_{1}$ - the angle of the crank of the $O V$ when moving the vehicle.

Then, taking into account expressions (12), the expression (11) takes the form:

$$
\omega_{1}=\frac{V_{A}}{r_{1}} \cdot \frac{d-\frac{x_{A}}{\tan \varphi_{1}}}{r_{1}-\frac{x_{A}}{\sin \varphi_{1}}}
$$

To determine the value of the angle $\varphi_{1}$, depending on the movement $x_{A}$, we project a broken line $O V A$ on the $O Y$ and $O X$ axis:

$$
\left\{\begin{array}{l}
r_{1} \cos \varphi_{1}+d-\ell \cos \varphi_{2}=0 \\
r_{2} \sin \varphi_{1}+x_{A}-\ell \sin \varphi_{2}=0
\end{array}\right.
$$

where $x_{A}$ is a shift of the point $A$ relative to the beginning of the coordinate system (the center of the tree trunk), $\mathrm{m} ; d$ - distance between the row line and the vehicle movement line, $\mathrm{m} ; \varphi_{1}$ - the angle of the crank of the $O V ; \varphi_{2}$ - the angle of the $A V$ crank rod.

From the second equation of the system (15) after the transformation we shall obtain:

$$
\cos \varphi_{2}=\sqrt{1-\left(\frac{r_{1} \sin \varphi_{1}+x_{A}}{\ell}\right)^{2}}=\frac{1}{\ell} \sqrt{\ell^{2}-\left(r_{1} \sin \varphi_{1}+x_{A}\right)^{2}} .
$$

Substituting the expression (17) in the first equation of the system (15), we shall obtain:

$$
r_{1} \cos \varphi_{1}+d=\sqrt{\ell^{2}-\left(r_{1} \sin \varphi_{1}+x_{A}\right)^{2}}
$$

From here, finally the expression for the $\varphi_{1}$ turn angle of the $O V$ crank in the function of variable distance $x_{A}$ will take the form:

$$
\varphi_{1}=\arctan \frac{x_{A}}{d}+\arccos \frac{\ell^{2}-r_{1}^{2}-d+x_{A}^{2}}{2 r_{1}^{2}} .
$$




\section{Conclusions}

When the unit moves along the line of the row, after the contact of the jack wheels with the tree trunk, through kinematic connections, the position of the design of the side-mounted turning section is changed relative to the tree trunk that allows, when turning the turning section around the tree trunk at the angle necessary for the complete mowing of vegetation in the zone of the near-trunk circle, which has common rotation axis with the jack wheels, rotors with cutting segments to move around the guide circle around the tree trunk.

\section{References}

1. A. K Apazhev, E. A. Polishchuk, Journal of Physics: Conference Series (JPCS), 1679 042086 (2020)

2. A. M. Atlaskirov, Y. A. Shekihachev, L. A. Shomakhov, Agrotechnical and economic efficiency of a rotary garden mower, 2, 164 (2020)

3. A. K Apazhev, Y. A. Shekikhachev, A. G. Fiapshev, L. M. Hazhmetov, International Scientific and Technical Conference Smart Energy Systems 2019 (SES-2019), 124 05054 (2020)

4. V. S. Bzheumykhov, Y. A. Shekikhachev, Z. V. Bzheumykhova, AgroEcoInfo, 4(30) (2017)

5. A. L. Khazhmetova, A. K. Apazhev, Yu. A. Shekikhachev, L. M. Khazhmetova, A. G. Fiapshev, Techniques and Equipment for countryside, 6(264), 23 (2019)

6. A. L. Khazhmetova, A. K. Apazhev, Yu. A. Shekikhachev, L. M. Khazhmetova, A. G. Fiapshev, AgroEcoInfo, 2(36), 29 (2019)

7. L. A. Shomakhov, Yu. A. Shekikhachev, R. A. Balkarov, Horticulture and Vine growing, 1, 7 (1999)

8. A. M. Egozhev, E. A. Polishchuk, A. A. Egozhev, Rural mechanizer, 12, 8 (2019)

9. A. K. Apazhev, Yu. A. Shekikhachev, L. M. Khazhmetov, The Gorsky State Agricultural University news, 53(2), 138 (2016)

10. A. K. Apazhev, Yu. A. Shekikhachev, L. M. Khazhmetov, The Gorsky State Agricultural University news, 53(2), 146 (2016)

11. A. Apazhev, V. Smelik, Y. Shekikhachev, L. Hazhmetov, Engineering for Rural Development, 18, 192 (2019)

12. A. K Apazhev, A. G. Fiaphev, Y. A. Shekikhachev, L. M. Hazhmetov, L. Z. Shekikhacheva, Earth and Environmental Science, 315(5), 052023 (2019) 